\title{
La desestabilización de Portugal en 1891 y la posición española
}

\author{
Pascual Serrano Sirvent
}

\section{RESUMEN}

Entre 1890 y 1893 Portugal vivió, como consecuencia del ultimatum inglés del 11 de enero de 1890, una

época de profunda inestabilidad política interna además de una fuerte crisis financiera que la agravó. En este momento, la Reina Viuda de Portugal,

Maria Pia, con el conocimiento del Gobierno portugués, comenzó a hacer

unas consultas a la Reina Regente Maria Cristina y el Gobierno español pidiendo una acción militar contra una posible revolución republicana con la aceptación de las primeras potencias europeas. Resultó que las primeras potencias europeas querían la permanencia del principio monárquico en Portugal, con una posible ayuga militar española al ejército de Portugal.

\section{PALABRAS CLAVE} Crisis, política, Portugal, 1891, petición, ayuda, militar, España, permiso, potencias, europeas.

\section{ABSTRACT}

Between 1890 and 1893, as a result of the English ultimatum of $11 \mathrm{~h}$ January 1890, Portugal went through a period of great instability, and also a great financial crack that turned into a political crack. This caused Widow Queen Maria Pia, with some knowledge of the Portuguese Gouvernmwnt, to ask Regent Queen Maria Cristina and the Spanish Gouvernment to help the Spanish Army against a possible republican revolution in Portugal, with the agreement of the main European powers. As a result, the main European powers wanted to keep the monarchy in Portugal, with the possible aid of the Spanish Army.

\section{KEY WORDS}

Politic, crisis, Portugal, 1891, aid, military, Spain, European powers. 


\section{ASPECTOS ESENCIALES DE LA POLITICA EXTERIOR ESPAÑOLA Y SU PROYECCIÓN HACIA PORTUGAL}

La comprensión de la política exterior española durante el siglo XIX, en sus diversos asuntos, no puede realizarse, sin antes observar las circunstancias generales del país. Pienso que todo país, todo Estado, es un organismo que vive en cada una de sus etapas temporales, incardinado dentro de una doble posición, interior y exterior, no existiendo posibilidad de entender la una sin la otra; no se trata de reiterar una idea común, sino de incidir llanamente en algo que con frecuencia no es tenido en cuenta en su debida importancia.

La posición geopolítica de España y Portugal cambia drásticamente en el siglo XIX respecto de los anteriores, al perderse la mayor parte de los territorios ultramarinos, su dimensión de poder adaptada a las posibilidades de cada país se hunde, a lo que ayuda, además, la necesidad de construcción de una nueva forma de Estado, el Estado Liberal, sobre el que no hay acuerdo interno pleno en ambas sociedades, de la misma manera que la nueva forma económica capitalista no acaba de ser vertebrada adecuadamente. Ambos países pasan a ser potencias claramente secundarias, tanto en el contexto europeo como mundial; desaparecen las antiguas rivalidades con Gran Bretaña y Francia, sobre todo por la imposibilidad de medirse con estos países que mantienen el rango de gran potencia. La idea clave del siglo XIX, en política exterior, será la dependencia luso-española de las líneas exteriores británicas y francesas.

La dependencia señalada está en directa correlación con las situaciones internas española y portuguesa, cuya característica más importante es la inestabilidad entendida como falta de solidez de sus respectivas organizaciones político-administrativas, que impide toda política exterior propia, autónoma, independiente.

Los aspectos generales de la política exterior española son los siguientes: primero, en la base una evidente penuria de medios y ¿qué es una política exterior sin medios?; segundo, una notable incoherencia respecto de los intereses nacionales reales, que lleva a resultados poco útiles; y tercero, una persistente situación de autoaislamiento respecto de los asuntos internacionales denominada recogimiento, lo que se traduce en una falta de apoyos exteriores ante situaciones delicadas (1, 2, 4).

La aludida carencia de medios está en relación con una organización inadecuada del Ministerio de Estado, unida a la falta de continuidad de los titulares de ese ministerio y del propio gobierno, lo que agudiza los problemas de la incoherencia y falta de eficacia de la política externa (2). 
La Restauración alfonsina, si bien introduce una estabilidad gubernamental antes desconocida, no altera los parámetros básicos de la acción exterior, a pesar de ser consciente de vivir en un contexto internacional del todo diferente, fruto de la emergencia de la potencia alemana y poco después de la estadounidense y japonesa en la escena internacional.

En el fondo, la política exterior española del diecinueve está mediatizada por la situación interna de un país inadaptado a los cambios producidos en los países más avanzados, lo que Don Antonio Cánovas del Castillo capta en su plenitud, al observar lo real de la debilidad económica de España, debilidad de medios a la que se supedita toda su idea de acción exterior; asume además los malos resultados de la precedente política de prestigio de los años sesenta; y se obsesiona con la necesidad de dotar de estabilidad a la recién reinstaurada monarquía; a su modo, asume la "realpolitik» predominante en su tiempo, pero es el suyo un realismo postrado, falto de miras, dado que habiendo entendido que no se puede ser protagonista sin una base material suficiente, no llega a "darse cuenta" que la única posibilidad de arbitrar una defensa mínima respecto de una gran potencia con aires expansionistas, consiste precisamente en comprometerse con otros países fuertes capaces de contrarrestar esa posible apetencia expansiva, de aquí nace la política de "recogimiento", que no significa necesarimente aislacionismo, ni neutralismo, sino conciencia de la propia debilidad y posibilidades, pero que conduce a ese tipo de situaciones (6).

Los gobiernos de la Restauración asumen muy escasos compromisos exteriores, dirigidos todos ellos a consolidar la estabilidad interior española y a mantener el status quo en el ámbito internacional, que para España supone garantizar la seguridad de los territorios ultramarinos insulares. En el interior, garantizar la consolidación de la monarquía alfonsina es prioritario para Cánovas, de ahí su acuerdo de principio con Alemania en diciembre de 1877, que pretende conseguir un cierto apoyo de las potencias centrales para contrarrestar las influencias desestabilizadoras que proyecta la Francia republicana, nótese que ni Cánovas ni Bismarck buscan una alianza, sino que el primero pretende un apoyo internacional a la estabilidad interior española, y el segundo evitar un posible conflicto en Europa (6).

En el ámbito internacional se sigue confiando en el respaldo francés y sobre todo británico al status quo territorial, que es únicamente implícito, dependiente de la voluntad inglesa de ampararlo, frente a la cada vez mayor presión norteamericana en las Antillas y de varias potencias en el Pacífico (japoneses y norteamericanos); postura conservadora con la que 
los liberales no están de acuerdo, por lo que cuando llegan al gobierno intentan una cierta apertura en los asuntos internacionales, un cierto compromiso, pero sin la preparación y decisión suficientes, lo que comporta un acercamiento hacia Alemania, a través de Italia, tanto en el primer gobierno de 1881-1884, como en el gobierno largo de 1885-1890. Se trata de un acercamiento sin demasiadas pretensiones por ambas partes, dado el escaso deseo de compromiso español y el exiguo interés alemán en un compromiso mayor, no existiendo adhesión al Tratado de la Triple Alianza (1), sino un canje de notas entre el ministro de Estado Moret, y el plenipotenciario de Italia en Madrid que era el marqués de Maffei, hecho el 4 de mayo de 1887, cuyo texto translitera Jerónimo Bécker $(1,700 / 701)$, en el que no se estipula forma alguna de actuación ante una crisis, $y$ al que se adhieren Viena y Berlín el 21 y 22 de mayo, siendo comunicado el acuerdo por el embajador de Italia en Londres a Lord Salisbury, el cual le ofrece sus simpatías, sin duda, por su inocuidad.

La evolución de los acontecimientos no incrementó el interés de ambas partes por acrecentar el endeble Acuerdo, dado que ni Alemania ni sus aliados se interesaron por la mejora del compromiso, y tampoco España lo solicitó. Cuando llegó el momento de la renovación en mayo de 1891, en España ya no gobernaban los liberales, verdaderos artífices del Acuerdo, sino Cánovas, al que agradaban poco las aventuras centroeuropeas, consciente de que los intereses españoles dependian del voluntarismo británico, en consecuencia, bien informado de la buena disposición de Inglaterra hacia la Triple Alianza, y tras la proposición e insistencia de Italia, terminó aceptando la renovación del Acuerdo, en los mismos términos que el anterior, dado que cumplía el importante papel de protección dinástica. No sucedió lo mismo en mayo de 1895, al guardar silencio ambas partes, lo que condujo a la extinción del Acuerdo por desinterés mutuo; tal vez cuando España más necesitaba de una vinculación internacional, ante el peligroso precedente del ultimatum inglés sobre Portugal de 1890 , no prestándose adecuada atención en Madrid al creciente peligro norteamericano; importa señalar, que el Acuerdo no generó actuaciones que resultasen positivas en la vida exterior española, subsistiendo un nada operativo acuerdo verbal con Italia (1).

Las relaciones entre España y Portugal en el tercer tercio del siglo XIX cabe definirlas como cordiales, si bien hubo momentos de cierta tensión, acompañados de otros más amplios de verdadera apatía o desinterés por cultivar esas relaciones. Al término de la etapa isabelina, el antiguo iberis. mo, es repudiado por ambos gobiernos, al ser causa de los elementos revolucionarios, dándose unas estrechísimas relaciones para oponerse a todo intento de desestabilización política en ambos países. El triunfo de la 
Revolución de Septiembre en España, produce un aumento de las tensiones, derivado de la confusión entre la cuestión de la candidatura al Trono de España y un concepto impositivo de iberismo que los progresistas españoles no defienden, pero que es frecuentemente el único que se entiente por tal al otro lado de la Raya. Enturbiadas así las relaciones, dado lo efímero de los gobiernos septembristas españoles y sus insuperables problemas internos (2), el deseo portugués de evitar el contagio revolucionario termina por paralizar las relaciones.

Con la llegada de la Restauración alfonsina se recupera el entendimiento entre ambos paises, al calor del desarrollo del Turnismo y del Rotativismo, formas semejantes de organización del proceso político (3), lo que se manifiesta en los siguientes aspectos: primero, se reemprende la antigua colaboración de la etapa isabelina contra las diversas formas de subversión; al mismo tiempo, consciente Cánovas del Castillo del perjuicio de la antigua idea iberista, para las relaciones mutuas, tiende a alejarla, y en tanto es asumida por partidos antisistema tal labor resulta más necesaria; por otra parte, el Tratado de la Cuádruple Alianza de 1834 había consolidado la dualidad peninsular, al tiempo que la tutoría inglesa de las relaciones interpeninsulares, y como ambos países necesitaban de la amistad británica, para garantizar sus intereses ultramarinos, y aún para su seguridad interior y dinástica, ello motivó que Cánovas considerase en todo momento la actitud inglesa a la hora de emprender cualquier acción de relación hacia Portugal; en cuarto lugar, puede decirse que en general las relaciones fueron cordiales, alcanzando el maximun a inicios de los años ochenta, con varias entrevistas entre Luis I y Alfonso XII (7), lo que no impidió que las relaciones volvieran a caer en una nueva situación apática, repitiéndose como tantas veces en el pasado una "vuelta de espaldas", presagio de consecuencias funestas para el futuro, que se prolongará hasta el Ultimatum de Inglaterra, $y$ tras unos meses de acercamiento entusiástico (3, $8,10,11$ ), vuelta al estado abúlico, enfermedad al parecer incurable.

\section{LA DESESTABILIZACIÓN INTERNA DE PORTUGAL A CONSECUENCIA DEL ULTIMATUM INGLÉS}

El fenómeno conocido como redistribución colonial, hace referencia al reequilibrio de poder ultramarino entre los paises que conservan o adquieren, en el siglo de la industrialización, el papel de gran potencia y los que lo pierden o mantienen con ciertas dificultades, siendo típico del último tercio del XIX. Portugal había pasado a ser un pequeño país con unas olvidadas tierras ultramarinas, esencialmente africanas, en las que invertía 
poco y obtenía menos, Brasil y no Africa siguió siendo en el XIX la tierra de promisión portuguesa; ausencia de motivación para la emigración portuguesa y dejadez gubernamental se unieron para que el africanismo portugués fuera poco efectivo, hasta bien entrada la segunda mitad del diecinueve, lo que contrastaba con el creciente y efectivo interés de los principales países europeos.

Cuatro fechas jalonan la crisis portuguesa: el ultimatum de 11 de enero de 1890 , el malogrado tratado de 20 de agosto y el modus vivendi de 15 de noviembre, ambos del mismo año, terminándose con el definitivo tratado ratificado por Portugal el 27 de junio de 1891 (8). Entre estas fechas, una opinión pública exaltada contra el viejo aliado inglés, que no tiene posibilidad de sustitución dada la tradicional dependencia portuguesa de aquél; una crisis financiera cuyo punto álgido está en la primavera de 1891; la pérdida de crédito de las instituciones y particularmente del régimen monárquico $(8,9,10,11)$. Estos acontecimientos producen el crecimiento de las tendencias republicanas, que nacidas bastante tiempo atrás, tienen ahora su posibilidad de consolidarse e intentar el cambio de régimen, tomando partido por el Portugal que no claudica; y por prematuro que pueda parecer, los republicanos más exaltados, ardorosos de cambio político, decididos a que los gobernantes que han permitido tal humillación no sobrevivan a la misma, van a protagonizar el precedente del futuro 5 de octubre de 1910, en la ciudad más avanzada y progresista de Portugal, es Oporto y estamos a 31 de enero de 1891 (3); testigo excepcional, el Cónsul español, describe los acontecimientos del modo siguiente:

"Según mis informes anoche se percibió movimiento sedicioso en las tropas que guarnecen esta capital atribuyendose su direccion á los sargentos de las mismas. En la madrugada se ha constituido en la Camara do concelho ó sea Ayuntamiento un grupo de republicanos dirigidos por el Doctor Alves da Veiga el cual despues de haberle sido franqueado todo el edificio en que habia guardia ha proclamado la Republica apoyado por el batallon de cazadores 10 parte del $18 \mathrm{y}$ otras fuerzas con las cuales dominan todo el centro de la ciudad. Segun me dicen han asesinado al Comandante de la Guardia Municipal y un jefe de artilleria. La Guardia municipal y parte del batallon $n^{0} 18$ aunque esta mas flojamente se vaten con los sublevados y hay bastantes bajas." (fuentes, 1) (*).

Continuando con la narración desde un punto de vista promonárquico, el Cónsul español en Oporto expone el fracaso de la revolución y sus consecuencias de tensión e inestabilidad política, de muertes y represión. La derrota de los revolucionarios es causada, al menos, por los siguientes factores:

(*) En todo texto transliterado se respeta la grafía original cualquiera que esta sea. 
primero, por confiar excesivamente en sus solas fuerzas; segundo, en cuanto no contaron con otros grupos sociales de la ciudad, falta de identificación del elitismo republicano con lo popular, sino cuando era demasiado tarde; y en tercer lugar, por no preveer la posible rápida respuesta de las fuerzas que se mantuvieran leales al régimen, como sucedió.

Pasada la tensión inmediata, el régimen intenta castigar a los responsables, pero es tal la debilidad en que se encuentran las instituciones, que careciendo de fuerzas para ello, se contenta con levísimas penas, lo cual llega a levantar protestas entre los más fieles monárquicos; sugiriendo esta falta de energia, un principio de intensa descomposición de la idea monárquica en Portugal, dada la incapacidad de la monarquía para castigar con contundencia a quienes han puesto en peligro de muerte al régimen (fuentes, 2 y 3 ).

\section{LA INESTABILIDAD POLITICA PORTUGUESA Y LA PETICIÓN DE APOYO A LOS PAÍSES MONÁRQUICOS AMIGOS}

El reinado de Carlos I de Portugal empieza en 1889, suscitándo una gran esperanza de mejora general en el pueblo, sin embargo, fue éste un rey con muy mala fortuna a pesar de sus excelentes propósitos y cualidades, que lo hacían digno continuador de su antecesor Luis I. Al rey Carlos le tocó pasar por la grave crisis del ultimatum inglés, y por una crisis económico-financiera intensa, de forma que las circunstancias le forzaron a abandonar el papel político neutral tan elogiable en su antecesor, motivando el desprestigio de su persona y de la institución monárquica, destruyéndose así su gran popularidad inicial.

La crisis del Estado portugués venía de lejos, no siendo posible entrar aquí en ella, baste decir, que su endeudamiento era enorme, de forma que cada presupuesto quedaba tan sujeto a la satisfacción de la deuda que no redundaba en acción de mejora para el pais, siendo éste el primer caso que conozco típico de deuda externa masiva, si a ello unimos el choque socio-político del ultimatum, y la adscripción de notables personalidades al republicanismo habiendo entrado en crisis el rotativismo, tenemos los ingredientes necesarios para el deterioro del régimen.

La dificultad de la situación era tal, que tanto los manárquicos más fieles como la propia familia real, temen por el régimen, por lo que no es de extrañar que se pida ayuda a las monarquías amigas, o más concretamente se las sondee, a fin de conocer su posición para el caso de que peligrando la monarquía en Portugal, sus autoridades soliciten ayuda en toda regla, se trata de estar prevenidos ante un nuevo movimiento como el de 
Oporto, gestiones que por vía diplomática muy reservada, lleva adelante la Reina Viuda Doña María Pía entre 1891 y 1893, las cuales vamos a analizar a continuación.

Nos encontramos ante una sucesión de textos diplomáticos de carácter reservado, cuya iniciativa proviene como se ha dicho de María Pía, los cuales recorren las principales cancillerias europeas indagando sobre el parecer de éstas, acerca de una posible ayuda efectiva exterior contra los revolucionarios republicanos si llegara el caso, teniendo el conjunto de ellos gran interés tanto por el asunto concreto como para el conocimiento de este tipo de "preparativos" en la época estudiada.

El siguiente texto, elaborado en el Ministerio de Estado, al objeto de comprender mejor las etapas del problema, clarifica los orígenes de la maniobra diplomática que vamos a analizar:

"La sublevacion republicana que tuvo lugar recientemente en Oporto, á la que, si bien dominada prontamente, siguió, sin embargo, una prolongada agitacion revolucionaria, creó un malestar en sentido antidinástico, que sostenido y fomentado por el conflicto con Inglaterra, á consecuencia de las discusiones de límites territoriales en las colonias y agravado sériamente por la fuerte crisis económica, por que aun atraviesa aquel Reino, tomó proporciones verdaderamente tan extraordinarias, que en toda Europa se ha tenido la convicción en estos tiempos, de que la revolucion era inminente en Portugal, temiendose estallára, de repente, como habia sucedido en el Brasil anterioremente.

En esta situacion, S.M. la Reina Regente, recibió en San Sebastián, una carta de la Reina María Pia de Portugal, preguntando, confidencialmente, si en el caso de que su Augusto Hijo el Rey Don Carlos, pidiera auxilio á España, para dominar una insurreccion probable, España le prestaria ayuda, enviando sus tropas á Portugal. (fuentes, 4).

La carta de la Reina Viuda portuguesa a que se hace referencia en las líneas del texto transliterado, no puede ser más explícita en la indicación de las causas del problema y la concreta petición de ayuda, estando fechada el 2 de agosto de 1891, en el palacio de Ajuda. Sus líneas centrales dicen asi:

“Notre pays, que j'adore, est très tourmenté par les républicains, que font leur travail tenacement pour faire mal au Roi ici et à nos institutions. Profitant de tous les malheurs qui nous frappèrent dernièrement, de toutes les manières, pendant la question de l'Afrique avec l'Ingleterre, puis celle de nos finances, qui en ce moment ne vont pas aussi bien que nous le désirions, pour nous en faire des griefs vis-à-vis de notre peuple. II pourrait y arriver une revolution, petite ou grande, je n'en sais rien. J'espère encore que non, et le Ministère et Charles l'espèrent aussi. Mais si elle arrivait, j'aimerais savoir en secret, si tu serais disposée, et si tu le pouvais ainsi que ton Ministère, l'Espagne enfin, venir à notre aide, pour la suffoquer et la détruire, 
si on te demandait aide officiellement, arrivée l'occasion, en envoyant ici, en amis sincères, une partie de votre armée, pour l'unir à la nôtre. A cette fin, si tu le voulais et le trouvais convenable, tu pourrais en parler, en secret, au Président du Conseil et m'envoyer la réponse, mais réelle, pour que je puisse la donner à Charles et au Président du Conseil, José Crisostomo, le nôtre, et pour que nous pussions, l'occasion venue, être sûrs de votre aide, sans aucun doute.» (fuentes, 8$)\left({ }^{\star \star}\right)$

No duda María Pía en pedir la máxima seguridad acerca de la ayuda a recibir, insistiendo en que se conspira para la revolución antidinástica también en España e Italia, bajo un cierto amparo francés, y que la vida de su hijo el Rey Carlos peligra.

Inmediatamente, María Cristina, que recibió la carta estando en San Sebastián, se comunicó con el Presidente del Consejo de Ministros, Sr. Cánovas, que habida cuenta de su extrema prudencia internacional, subordinó la ayuda a su aceptación por las potencias, telegrafió inmediatamente al Ministro de Estado, que era D. Carlos O'Donnell y Abréu, $\|^{\circ}$ Duque de Tetuán, comunicándole la petición portuguesa el 7 de agosto, y requiriendo urgentes gestiones cerca del gobierno italiano, a través del embajador Sr. Benomar. Es así como se inicia el que vamos a llamar «camino diplomático italiano" (fuentes, 5).

La Reina Regente consultó al Sr. Práxedes Mateo Sagasta sobre la cuestión, que le expuso su opinión en cuatro consideraciones, con fecha de 10 de agosto: primera, la intervención sería antes de que se proclame la república; segunda, el ejército cuidaría del orden público en España; tercera, debería tratarse el tema de la indemnización; cuarta, era necesario contar con el beneplácito de Alemania (fuentes, 6).

En Italia, el sucesor de Crispi, Sr. Rudini, se mostró impresionado por la gravedad de la situación interna portuguesa, la cual desconocia, pero ello no le impidió aconsejar la mayor prudencia a fin de evitar pretexto alguno que provocase una guerra europea, por lo que era preciso consultar a los países aliados de la Triplice, a Inglaterra, y quizá a Francia, con la que no deseaba malentendidos de ningún tipo $(7,243)$.

Tras los telegramas del Conde de Benomar desde la embajada en Roma en la noche del día diez, en los que se expresaba la invitación italiana a una gran prudencia y a la realización de las consultas pertinentes,

(**) Parte de las cartas fueron localizadas en el Archivo del Palacio Real y publicadas por Salom Costa en el artículo indicado, apareciendo en ellas la trama esencial del proceso, pero éste no estudió la documentación del Archivo del Ministerio de Asuntos Exteriores, de mayor extensión, que he podido localizar y trabajar, siendo el resultado el presente artículo. 
Cánovas acordó con la Reina Regente la respuesta que debía dar a María Pía, que expuso en un autógrafo a lápiz, fechado el día once en Biarritz, cuyo texto es el siguiente:

"Que en el estado de Europa sería imprudente para nosotros llevar á Portugal nuestras tropas sin el conocimiento y aun el apoyo moral de las grandes Monarquias y en particular de la Triple alianza de que Italia forma parte. Que sabemos que esa es la opinion de Italia que tan indudables simpatías profesa á la Monarquía portuguesa. Que antes de tomar una resolucion que entre nosotros no ofrece dificultad alguna, necesitamos su própio apoyo cerca del Rey de Italia y su autorizacion para entablar las negociaciones confidenciales que este grave asunto requiere antes de darle forma oficial.» (fuente, 7 )

Como vemos, Cánovas no encuentra objeción a ese apoyo, que está dentro de su tradicional política de estabilidad y defensa dinástica, siempre que se cumplan algunos requisitos formales de suma importancia; uno de ellos, es el acuerdo de las potencias, tras ser informadas del asunto; otro, el acompañamiento de la petición por las formalidades oficiales necesarias; y el tercero, una autorización formal por parte del Gobierno portugués para iniciar gestiones. Queda clara la prudencia de Cánovas, y la semejanza de esta pretendida intervención a la del general Rodil en 1834 , y la del general Concha en 1847, aumentando en esta ocasión la prudencia, es decir, la ausencia de toda actitud negativa, y mucho menos agresiva, hacia Portugal, por parte española; encontrándose esta mentada intervención dentro de la mediatización británica de las relaciones interpeninsulares, como las dos anteriores.

La respuesta de la Reina Regente a María Pía se produce el 12 de agosto, desde San Sebastián, conteniéndose en ella los extremos que hemos visto en el texto de Cánovas, y tras insistir en la necesidad del apoyo de las grandes Monarquías, dice:

“Donc, pour rendre possible la solution qui est l'objet de ta demande et qui n'est pour nous d'aucune difficulté, il sera convenable que tu t'adresses à ton Frère, le Roi d'Italie, pour le convaincre de la necessité de te prêter son appui, et qu'en même temps tu me donnes l'autorisation de confier à mon Goubernement les soins des negotiations confidentielles, indispensables dans cette grave démarche, avant de les emtamer officiellement. (fuentes, 9)

Como vemos, tres son los puntos, en que la Regente insiste: la disposición a dar la ayuda sin problemas, la necesidad que desde Portugal se pida el apoyo del Rey de Italia, y la formalización oficial de la petición para que España pueda empezar las gestiones. Pero el mismo 12 de agosto, 
María Cristina, a inicitiva suya, escribe a la Reina Victoria, exponiéndole el problema y la petición portuguesa con detenimiento, iniciándose así lo que denominaremos "el camino diplomático inglés", lo cual no es extraño según se ha dicho con anterioridad; en efecto, si con el apoyo italiano se garantiza la buena disposición de la Triplice, faltaba la conformidad británica, sin la que, en realidad, ninguna gestión de este tipo habría triunfado, en la Europa del momento. Nada más explicito que sus propias palabras:

“(...), cuando recibí, hace pocos días, una carta de la Reina María Pía, en la que me pregunta, con toda confianza y con el mayor secreto, como sería acogida por mi gobierno una peticion oficial, en la cual Portugal rogase a España mandara tropas en auxilio del ejército portugués, para el caso de estallar la revolucion en Portugal. Claro está que mi propia opinion es, que en interés del principio monárquico, para el mantenimiento del status quo y de la paz europea, es preciso que se apoye la monarquia en Portugal. Dos veces ya (1834 y 1847) intervinieron nuestras tropas en Portugal para restablecer la paz en el país, y esto siempre ha sucedido así de acuerdo con Inglaterra. (...)» (fuentes, 10).

De esta forma, el país que ha creado las circunstancias detonantes de la crisis portuguesa, en virtud de su control de las relaciones interpeninsulares y de sus propios intereses, va a verse en cierto modo obligado a hacer lo posible por evitar la consecuencia más negativa, cual es la caída de la monarquía portuguesa, pobre pago para tanto tiempo de tan peculiar y desequilibrada alianza, o quizá debamos decir pura y simple dependencia. Destaquemos la claridad de la Regente a la hora de expresar lo que se pretende y su insistencia en cuatro cosas, tan presentes en todo el siglo: importancia del principio monárquico, lucha contra los revolucionarios, mantenimiento del status quo, y aceptación de buen grado de la tutela inglesa de la acción exterior española, en particular en todo lo referido a Portugal.

La respuesta de la Reina Victoria, fechada en Osborne el 22 de agosto, no pudo ser más clara, en tanto lo que se le pedía estaba dentro de su política europea, y tras expresar que ya andaban preocupados por la situación interna portuguesa, dice:

«(..) Por parte del Gobierno inglés, que sean conservadores o radicales (liberales), de fijo no tendrá oposición alguna. El único peligro de temer sería Francia. La opinión pública en aquel país trataría probablemente de favorecer la República portuguesa. Por otra parte, Francia, en los actuales momentos nada querrá hacer que desagrade a Rusia. Se sabe de modo positivo que el Emperador de Rusia reconoce todo el peligro de la República en Portugal. (...)" (fuentes, 11)

El visto bueno de la Reina Victoria, a la iniciativa de María Cristina, añadido a los mejores deseos del Gobierno británico encabezado por 
Salisbury, se une a la sugerencia inglesa para que la Regente acuda a los buenos oficios de Rusia, a fin de frenar la posible iniciativa negativa de Francia; lo que indica que conoce el acercamiento que se está iniciando entre franceses y rusos, cuya alianza se hará pública en 1894, datando de dos años antes, es decir, que las fechas en las que nos encontramos fueron cruciales en el acercamiento franco-ruso, cosa que impedía una posición contraria de Francia en la cuestión si Rusia asentía. Sugiere, la Reina Victoria, que la mejor forma de comunicarse con el Zar es a través de su hijo Alfredo, de lo que tomará buena nota María Cristina.

Con fecha del día 18 de agosto, María Pía, había respondido a la Reina Regente, sobre las peticiones ya comentadas. En su contestación dice que también el 2 de agosto escribió a su hermano Humberto, y aunque no ha recibido la respuesta la espera positiva en virtud de la amistad que les une, de lo que se deduce que resulta probable una postura favorable de la Triplice; ahora bien, en la importante cuestión de formalización de la petición de ayuda, la Reina Viuda portuguesa dice:

«(..) Mais tout cela demandé seulement officieusement, mais pas officiellement, en famille, avec le consentement de notre Roi et du Ministère. (...) Ce que nous désirons c'est que officieusement et un secret tu fasses, si tu le veux et ton gouvernement, les démarches nécessaires auprès des grandes Monarchies et la triple alliance, pour avoir leur appui moral, pour pouvoir nous aider en cas d'une révolution républicaine ici, contre la Monarchie, en y entrant avec vos troupes en amis, nous aidant à y rétablir l'ordre, sans que cela soit officiellement traité et en gardant tout le secret jusqu'à ce que officiellement, si le cas se présentait, nous puissions te demander l'aide, (...)" (fuentes, 12)

Con toda precisión expresa María Pía, la decisión de ella, del Rey y del Gobierno portugués, de pedir consultas oficiosas, preliminares, pero no de dar una autorización oficial para tales consultas, la cual llegaría únicamente si se presentara la situación de peligro y alarma pertinente; es decir, todo debe quedar resuelto en los contactos oficiosos muy reservados al más alto nivel, y la autorización oficial sería para la entrada de tropas en el momento necesario e inevitable.

Desde San Sebastián, donde sigue en periodo vacacional Maria Cristina, con fecha de 22 de agosto, responde a María Pía, aceptando plenamente la autorización preliminar u oficiosa de las gestiones, "(...) nous ferons une usage tout à fait confidentiel, officieux et secret. (...)", dice; al tiempo que manifiesta su pretensión de mantenerla informada puntualmente de todas las gestiones, y ruega que ella también lo haga respecto de lo que considerase oportuno (fuentes, 13). 
A estas alturas de la exposición observamos la existencia de "dos líneas", o como hemos denominado anteriormente "caminos" diplomáticos, a fin de conseguir el éxito de las gestiones dirigidas a que la tambaleante monarquia portuguesa sea apoyada en las diversas cortes europeas: el primero es el italiano, que conduce a la consecución de la conformidad de la Triple Alianza; el segundo, no menos importante, es el británico, que lleva a la neutralización de Francia a través de la presión rusa. Se trata de una operación diplomática que de haberse materializado mediante una intervención en toda regla, tras la correspondiente petición formal portuguesa, habría pasado a la historia como clásica en su genero, habida cuenta de la cantidad y calidad de las gestiones realizadas, el desarrollo histórico quiso que la necesidad de ayuda llegase cerca de dos décadas después, cuando estas gestiones habían perdido vigencia, y en unas circunstancias nuevas que las hacian no renovables.

En una carta de finales de agosto, en la que no se precisa el día pero por su contenido es posterior a la del 22 ya indicada, la Reina Regente expone a María Pía su carta a la Reina Victoria, en cuya respuesta le recomienda que consulte con el Zar Alejandro, al tiempo que expone su aprobación y la de su Gobierno, tanto si está detentado por conservadores como por liberales, a fin de ayudar a la estabilidad de Portugal, estando en su comienzo la gestión con Rusia. Pero lo más preocupante de este texto es cuando habla de una peligrosa filtración a la prensa de origen desconocido, que afirmaba que María Pía había escrito a la Reina Regente, lo cual la entristece más cuanto ha llevado el máximo cuidado y discreción, descifrando ella misma los telegramas remitidos por el Ministro de Estado, exponiendo a María Pía que solamente los jefes de los partidos monárquicos y el Ministro de Estado están al corriente de la gestión, y añade:

"(...) Nous avons fait rectifier la nouvelle, avec grande énergie, et l'on n'en parlera plus, je l'espère, et heureusement on n'a pas donné crédit à la nouvelle: on ne l'a pas cru. (...)" (fuentes, 17).

El desmentido a los indiscretos periódicos fue fulminante, pues la noticia no trascendió, fue tenida por falsa, continuando las gestiones en el máximo secreto, hasta el año 1893 en que finalizan, y sumiéndose después en un completo olvido, hasta que los historiadores la han estudiado.

Continua el "camino diplomático británico", escuchando el consejo de la Reina Victoria, por lo que el jefe del gabinete particular del Duque de Tetuán, Don Antonio Baguer, partió hacia Coburgo, donde se encontraba el príncipe Alfredo de Edimburgo, con una carta personal en la que María Cristina solicitaba sus buenos oficios en el asunto, su disponibilidad permitió que Baguer fuese a Copenhague donde le fue posible entregar a 
Alejandro III otra carta en la que se exponían las particularidades del asunto y se pedía su apoyo a fin de llevarlo a buen término. Tras examinar el asunto, el Zar, que ya tenía noticias de la inestabilidad en Portugal, aceptó presionar a Francia para que no adoptase una actitud contraria a la estabilidad de la Monarquía portuguesa. Con estas seguridades la Reina Regente se dirigió a Alejandro, cuya respuesta positiva llegó en octubre, desde Fredensborg, en los siguientes términos:

«(..) Tout le possible sera tenté dans le but demener le Gouvernement française à observer éventuellement une neutralité souhaitable pour le cas ou les troubles intérieures, dont le Portugal se trouve menacé, rendraient nécessaire l'intervention militaire de l'Espagne. (...)" (fuentes, 14).

La gestión diplomática a través de la mediación británica casi ha llegado a buen término, pues en el estado de ese momento de las relaciones intereuropeas, a lo cual debe añadirse el carácter predominantemente conservador tanto en el interior como en lo exterior de la III República, era del todo improbable que el Gobierno francés adoptase una posición que desagradase a Rusia. No obstante, indica el Zar, que siendo posible convencer a las autoridades francesas, no será lo mismo con las cámaras parlamentarias, las cuales habitualmente tienen una posición antimonárquica.

A mediados de octubre, al comunicar el embajador Benomar la entrevista habida en Monza entre el Sr. Rudini y el canciller ruso Giers, expone como sobre el asunto portugués se expresó en los mejores términos, indicando que estaba informado de la mejoría de la situación, que el embajador ruso en Roma se encontraba al corriente del tema, y que no siendo ahora necesaria mayor gestión si en el futuro lo fuere no habría problema en realizarla, siempre intercambiando ideas con Italia, sin duda, aquí debemos entender que esas hipotéticas gestiones se referirian a conseguir la buena disposición francesa (fuentes, 20). Esta mejoría de la situación interna portuguesa era conocida en Madrid a través de nuestra legación en Lisboa y la embajada en Roma.

En diciembre, la Reina Regente se vuelve a comunicar con el Zar Alejandro, que en su respuesta, le dice que su canciller Giers ha sondeado a las autoridades francesas con resultado francamente positivo, a una posible ayuda española al mantenimiento de la monarquía en Portugal, si necesario fuere, expresándose en los siguientes términos:

“(...) Mon Ministre des Affaires étrangères n'a pas manqué de sonder prudemment les dispositions du Gouvernement française, lors de son récent séjour à Paris, et les impressions qu'il en a rapportées sont des plus favorables. (...)» (fuentes 16). 
Las excelentes disposiciones de los gobernantes franceses están en relación, según Giers comenta al Zar, con su firme propósito de consolidar una república fundamentalmente conservadora, por lo que temen que una desestabilización en la Península no dejaria de afectar a Francia, razón suficiente para negar su apoyo a cualquier tentativa revolucionaria al sur de los Pirineos, cosa que no deja de mostrarnos una vez más los aires notablemente monárquicos del republicanismo francés, tanto de este momento como de otros.

A esta carta de contenido tan positivo, dado que supone la culminación con total éxito de la gestión iniciada por la vía británica, contesta María Cristina, el 12 de enero de 1892, agradeciendo profundamente los buenos oficios de Alejandro con las siguientes palabras:

"(...) Ces informations confidentielles de son Ministre des Affaires Étrangères, je les reçois et les apprécie dans toute leur importance, reconnaissant en même temps la bienveillance que Votre Majesté a consenti à porter dans cette delicate affaire et sa solicitude à me prêter son puissant appui, qui ne peut que ramener toutes mes espérances dans le triomphe de la cause monarchique en Portugal. (...)» (fuentes 18).

Contrariamente a lo que hemos visto en la posición anglo-rusa, el que hemos llamado "camino diplomático italiano" resulta ser tortuoso y difícil. Más atrás se ha podido ver como la impresión italiana a la primera comunicación española sobre el asunto fue de alarma, sobre todo temiendo una reacción violenta de Francia, al señalar el peligro que existía de guerra europea, por lo que se recomendó al Gobierno español una gran prudencia; cuando Rudini conoce la buena predisposición británica su opinión empieza a cambiar; al tiempo el Rey Humberto informado del peligro por el que atraviesa la Monarquía portuguesa por su hermana la Reina Viuda de Portugal, le ofrece su mejor predisposición en lo que a la posición italiana se refiere, $y$ en sus buenos oficios respecto de la Triple Alianza a la que pertenece; todo lo cual lleva a una aceptación de la petición española de comunicar a sus aliados centroeuropeos el asunto para que se pronuncien.

La comunicación del propósito español de sostener la causa monárquica en Portugal, incluso mediante intervención acordada con las autoridades portuguesas, si necesario fuera, produce en Viena una impresión favorable, no en vano Austria-Hungria era la tierra del legitimismo; pero no sucede lo mismo en Alemania, cuya respuesta es negativa, aunque sin aducir razones concretas, si bien la ausencia del canciller Von Caprivi y del Emperador Guillermo dan a esta respuesta un tono menor, provisional, siendo preciso aguardar al regreso de los embajadores alemán y austriaco a Madrid, junto a posibles gestiones nuevas de los embajadores españoles 
en Viena y Berlín, que son enterados del asunto, para darle adecuada salida, dado que en general parece poco probable que Alemania no llegue a compartir el parecer de sus aliados de la Triplice (fuentes, 19).

Habiendo las gestiones reservadas llegado a su fin, por lo menos preliminar, y congratulándose María Cristina de la recuperación de los partidos monárquicos portugueses, y de la mejora de la situación general interna, en carta desde Madrid, en noviembre de 1891, pasa a informar a la Reina Viuda Maria Pia del resultado de sus iniciativas, con las siguientes palabras:

“(...) La Reine d'Angleterre et l'Empereur de Russie, ont reconnu, en songeant à l'intérêt du principe monarchique et aux graves conséquences qu'une révolution républicaine en Portugal pourrait produire, que l'Espagne ne devrait guère recontrer difficultés à faire entrer ses troupes pour vous aider, ainsi que tu me l'avais demandé dans ta lettre, d'accord le Roi Charles et son Gouvernement. Je puis même ajouter que, dans cette délicate affaire, la Reine Victoire et l'Empereur Alexandre ont trouvé très justifié que nous prétions notre secours, et y on donné leur approbation; bien que Leur Majestés aient, en même temps, exprimé de l'incertitude à l'egard de l'attitude que la France pourrait prende au moment donné.

Touchant la triple alliance, je suppose que le Roi Humbert t'aura déjà informé des dispositions favorables de Italie et l'Autriche-Hungrie, ainsi que des vues réservées de l'Alemagne.(...)" (fuentes 15).

La gestión que ahora concluye, aunque provisionalmente como veremos, alcanza un completo éxito por partida doble: de un lado, las potencias dan su aprobación excepto la conocida reserva alemana; por otro, al mejorar la situación portuguesa deja de ser necesaria su ejecución.

Se trata, en definitiva, de un asunto sumamente revelador respecto de la entidad que tienen las relaciones ibéricas, y la mediatización que las relaciones peninsulares soportan; la debilidad frente a una posible revolución une a las autoridades de ambos países, estrecha sus relaciones, no siendo causa de unión el propósito de crear una auténtica comunidad de intereses que los haga fuertes, de lo que la mencionada crisis del ultimatum es el mejor ejemplo ( 8 y 11 ); lo anterior hace necesaria la mediatización exterior inglesa, pero también de otras potencias, particularmente para las cuestiones de cierta importancia.

\section{LAS GESTIONES DE 1893}

La vida portuguesa se había apaciguado a fines de 1891, y esa tendencia continuó en el año siguiente, pero seguía siendo evidente la debili- 
dad de las instituciones, del régimen monárquico, esa es la razón que fuerza a la Reina María Pía a insistir en las gestiones que ya conocemos, con el fin de obtener mayores garantías que las expuestas. Realmente, lo más importante que restaba concretar era la consecución de una clarificación de la reserva alemana, por lo que de problema pudiera entrañar, para el caso en que las circunstancias forzaran a una intervención española en Portugal en apoyo de la Monarquía.

En la primavera de 1893, María Pía, realiza un viaje por Europa, cuyo principal objetivo es la visita a Italia, donde espera ver a su hermano, el Rey Humberto. Esa cincunstancia piensa aprovecharla, para volver a poner sobre la mesa, el tema de la asistencia militar a Portugal en caso de peligro para su Monarquía; sin embargo, en carta escrita a la Reina Regente desde París el 16 de abril, expone además la posibilidad de incluir a España en las gestiones de la siguiente manera:

"(...) Mais je désir savoir toi bien ou sûre si tu veux aussi que dans le même sens je parle de l'Espagne et de sa dinastie pour que tous les pays monarchiques, arrivée une occasion nécessaire fussant unis par les uns les autres entre eux contre les republicaines, socialistes, pour y conserver leurs thrônes et ainsi assurer la paix de leurs pays. (...)" (fuentes 21).

Curiosa es la pretensión de la Reina Viuda de Portugal, por cuanto en España no se atraviesa por ninguna crisis de sistema político en este momento, dejando abierta en su idea tanto una inclusión formal de España en esas "conversaciones" como una mención oficiosa, según decida la Reina Regente; iniciativa ésta que se encuentra en relación con una reunión de varios príncipes, auspiciada por el Rey Humberto I, la cual tendrá lugar en Italia, siendo posible utilizarla para poner sobre le mesa el asunto de apoyo monárquico a Portugal, y según María Pía, también a España.

Desde Madrid, en carta de 26 de abril, María Cristina responde a la Reina Viuda, agradeciéndole su preocupación por España, pero indicándole que en las actuales circunstancias no sería positivo para la mejor solución de las necesidades de apoyo a la monarquía en Portugal, incluir a España en el asunto, y lo expresa con las siguientes palabras:

“(...) Je ne pense pas que l'occasion serait propice pour mêler à les demarches aucune autre affaire. Je crains même que tout nouveau sujet introduit dans la negociation si heureusement entamé, el dont les résultats ont été si bons pour son pays, pourra nuire à les démarches. (...)" (fuentes 21).

Ciertamente carece de base real esa pretensión de María Pía, y así se lo hace saber amablemente María Cristina; no obstante, si se interesa 
la Regente por los movimientos revolucionarios en Europa de raíz socialista, y en ese sentido, sugiere a la Reina Viuda que no sería sobrado sondear a la Monarquías europeas, para conocer su pensamiento sobre el asunto.

Alemania fue consultada sobre el problema de la inestabilidad interna portuguesa, y en su respuesta, conocida a fines de abril de 1893, consideró que se exageraba la situación, por lo que no debía tomarse ninguna iniciativa que pudiera amenazar la paz en Europa, sobre todo si Francia se oponia, expresando lo peligroso de las aventuras respecto de la paz europea. Contundentemente, el Emperador de Alemania llegó a decir al Rey Humberto, respecto de María Pía que:

«(..) las mujeres, cuando no eran soberanas reinantes, debian vivir completamente alejadas de la política, (...)" (fuentes 22).

Es preciso que no nos dejemos llevar por la primera impresión que puedan causarnos las anteriores palabras, pues Guillermo no pretende minusvalorar el papel de la Reina Viuda, sino simplemente expresar su enfado ante una posible acción internacional que no desea o no entiende oportuna; tanto es así, que Humberto le convenció del peso de María Pía en Portugal y de la necesidad de ayudar a la estabilidad es ese país, consiguiendo que intercediera para que los acreedores alemanes aceptasen un mejor trato a Portugal, conforme había propuesto en las Cortes el Rey Carlos.

Realmente se consideraba entre las autoridades alemanas, y en parte las italianas, que el mayor peligro al mantenimiento de la monarquía en Portugal, no venía de las acciones de los republicanos, que a sus ojos carecían de jefes capaces de hacer cosas efectivas, sino de la camarilla de incompetentes que rodeaba al Rey Carlos, y de la conducta poco responsable de la Reina Amalia.

A su regreso de Italia, María Pía pasa por Madrid e informa al Sr. Sagasta, que entonces presidía el Consejo de Ministros, durante la recepción del 13 de julio, que había obtenido del Rey Humberto y del propio Emperador de Alemania la promesa formal que en caso de desestabilización peninsular por un movimiento socialista o revolucionario, que pusiera en peligro una $u$ otra monarquía, mandarían sus flotas a los puertos de uno $u$ otro país, a fin de prestar todo el apoyo material y moral posible, que las circunstancias exigieran, a la causa monárquica, no siendo posible ayudar con fuerzas terrestes porque Francia no lo permitiría, ni siquiera en calidad de fuerzas de desembarco, en cuanto significaría intervención en los asuntos internos de otro país; además, ambos soberanos harían valer 
su influencia cerca del Emperador de Rusia a fin de conseguir su beneplácito a las acciones que en su momento fueran necesarias.

Con estas gestiones finaliza este asunto diplomático que nunca se materializó, al no darse las circunstancias necesarias para ello; sin embargo, esto no obsta para que lo consideremos como un asunto diplomático de corte clásico, que preocupó durante un tiempo a las cancillerías europeas, y que pudo haber dado lugar a una intensa crisis europea, si la revolución se hubiera apoderado de Portugal veinte años antes de cuando lo hizo.

\section{CONCLUSIONES}

Desde dos ópticas debemos considerar las conclusiones de este asunto diplomático: una interna y otra internacional, con el fin de conseguir su adecuada compresión. Vamos a considerar primero la internacional, que aparecera subdividida en varias partes según los países de que tratemos.

La vertiente internacional del asunto nos muestra los pareceres políticos de los dirigentes de la Europa de la «Paz Armada», así como sus desconfianzas y prevenciones. La gestión con Gran Bretaña que consigue el asentimiento francés vía Rusia, apenas plantea problemas; los británicos desean reparar el entuerto provocado por su ultimatum de 1890 sobre Portugal, el Zar no puede sino reincidir en su legitimismo, la República francesa siempre tan conservadora y monárquica no puede contradecir los deseos rusos; si por estos gobiernos hubiera sido, de darse las circunstancias pertinentes la intervención salvadora de la monarquía en Portugal hubiera tenido lugar.

¿Y la Triple Alianza? los italianos no deseaban el más mínimo pretexto de conflicto con Francia, conscientes como eran de su inferioridad militar, al mismo tiempo estimaban mucho el parecer británico en todo, sabedores que la III República no se indispondría con el poder británico, que en el Mediterráneo equilibraba las fuerzas italianas a las francesas, por tanto, se tranquilizaron cuando supieron del beneplácito británico a la posible acción española; los austro-húngaros eran tan legitimistas como los rusos y no opusieron obstáculos a algo que quedaba muy lejos de sus zonas de interés; Alemania fue el único problema real pero ¿se hubiera atrevido el Kaiser a desagradar el parecer de la Reina Victoria, cuando en estos años se buscaba una buena inteligencia con el poder británico, al tiempo que se dejaba de lado a los rusos? y ¿hubieran los alemanes hecho caso omiso del asentimiento de todas las potencias, incluidas sus aliadas? la respuesta se demoró cierto tiempo, pero de ningún modo fue negativa, no podía serlo, y Alemania hizo al tiempo gala de una gran prudencia ¿acaso 
le preocupaba el emergente tema de Marruecos como menciona Salom Costa? o ¿tenían en mente ya la apetencia por las colonias portuguesas africanas que más adelante manifestarán? resulta muy difícil saberlo; pero en todo caso tenían un acuerdo político con España, y no parece que buscasen desavenencias grandes con Francia, ni mucho menos con Gran Bretaña, en este momento, lo que hace perfectamente comprensible la respuesta que dieron, en unión de los italianos, sobre apoyo político-moral a las monarquías peninsulares, unido al de sus armadas si la ocasión se presentase, y ello siempre sin contravenir a los británicos y franceses.

Elevando la vista un poco sobre el discurrir diplomático, debemos notar, que son los británicos los que mantienen un criterio propio durante todo el proceso, y es su parecer el que convence a todos los demás, por mucho que coincida con la idea que se les transmite desde Portugal vía España; solamente los alemanes intentan, sin consecuencia, un criterio propio. El éxito de la gestión es puramente británico.

¿Y en todo esto dónde quedan los Estados peninsulares en cuanto tales? Si esta gestión fue necesaria, ella solamente puede explicarse atendiendo a la debilidad interna que desde principios de siglo arrastra el Estado portugués, que torna la "Alianza inglesa" en un auténtico protectorado; el papel de intermediario, en su caso brazo ejecutor, que desempeña España, la ubica dentro de la red diplomática británica, mostrándose así su control de los asuntos peninsulares. Potencias menores de la misma zona geográfica, que no son capaces de solucionar un problema interior, solicitan la ayuda de las grandes potencias del momento, pero no como consulta y negociación sino como autorización necesaria para hecer algo, autorización de la que, con permiso de los revolucionarios, depende la vida del sistema político portugués; todo lo cual indica la más completa dependencia de los dos débiles países respecto de las Potencias. Y esa dependencia reduce al mínimo la posibilidades de la política exterior de los países ibéricos, entendida ésta como algo propio de cada Estado, es decir autónoma, lo que está en íntima relación con los fuertes problemas de modernización económico-social y política que lastran a Portugal y España durante todo el $X I X$, a los cuales se ha hecho referencia al principio del artículo.

Como comentario final, es preciso detenerse en algunas ideas clave del discurso político de la época en lo internacional: la primera, es el principio monárquico, es decir, la solidaridad entre reyes y emperadores contra todo movimiento revolucionario republicano o socialista, lo que en todos los paises tiene una lectura interna, pero particularmente en los países ibéricos en lo referente a la permanencia de sus regímenes, teniendo la III República un comportamiento opuesto al fomento del republicanismo, aquí 
cabe ubicar el apoyo español sin reservas a la petición de ayuda portuguesa, que los principales países europeos van a compartir; y la segunda, es la vigilancia del status quo, todos los países se vigilan, en un mundo con cada vez mayor cantidad y calidad de los armamentos, y ello comporta el respeto mutuo a las situaciones adquiridas a fin de evitar el enfrentamiento, lo que impone una Europa de pactos, acuerdos, repartos de tierras o de intereses económicos previo entendimiento, prevención de desestabilizaciones, amenazas y guerras, en definitiva, búsqueda del equilibrio de poderes.

\section{BIBLIOGRAFÍA}

(1) BÉCKER, Jerónimo: Histoira de las relaciones internacionales de España durante el siglo xIx, Madrid, tipografia de Jaime Ratés, 1924, tomo III, págs. 974.

(2) LOPEZ CORDÓN CORTEZO, M $\mathrm{M}^{\mathrm{a}}$.: "La política exterior", Madrid, Espasa-Calpe, 1988. págs. 820-890 (véase el tomo XXXIV de la enciclopedia de Historia de España de Ramón Menéndez Pidal, dirigida por José Maria Jover Zamora, ISBN: 84-239-4982-6).

(3) Oliverira Maroués, A.H. de: História de Portugal, Lisboa, Palas Editores, março de 1986, volumen $11^{\circ}, 3^{\text {a }}$ ediçao, págs. 696.

(4) Pereira, Juan Carlos: Introducción al estudio de la política exterior de España (siglos $x \mid x$ y $x \times$ ), Madrid, Akal, 1983, págs. 255, ISBN: 84-7339-639-1.

(5) Rocamora, José Antonio: El nacionalismo ibérico (1792-1936), Valladolid, Universidad, 1994, págs. 205, ISBN: 84-7762-404-6.

(6) Salom COSTA, Julio: España en la Europa de Bismarck, Madrid, CSIC, 1967, págs. 434,

(7) SALOM COSTA, Julio: "La relación hispano-portuguesa al término de la época iberista", Hispania, número 98, mayo de 1965.

(8) Severiano Teixeira, Nino: O Ultimatum Inglês, Lisboa, Alfa, 1990, págs. 165.

(9) Soares Martinez, Pedro Mário: História Diplomática de Portugal, Lisboa, Verbo, maio de 1986, págs. 615.

(10) VAzOUEz Cuesta, Pilar: "Un 'noventa y ocho' portugués: el Ultimatum de 1890 y su repercusión en España", en El siglo XIX en España: Doce estudios, Barcelona, Planeta, 1974 , págs. 465 a 569.

(11) Vazouez Cuesta, Pilar: Espanha ante o ultimatum, Lisboa, Horizonte, 1975, págs. 240.

\section{FUENTES DE ARCHIVO}

(1) AMAE, despacho número 2, del Cónsul de España en Oporto al Ministro de Estado, legajo 2635 de Politica de Portugal, fechado en la mañana del 31-1-1891.

(2) AMAE, despacho número 3, del Cónsul de España en Oporto al Ministro de Estado, legajo 2635 de Política de Portugal, fechado en la noche del 31-1-1891.

(3) AMAE, despacho número 27, del Ministro de España en Lisboa al Ministro de Estado, legajo 1701 de Correspondencia de Portugal, con fecha de 12-1-1891.

(4) AMAE, documento número Sub-A-I, legajo 2635 de Política de Portugal, con fecha de 28-1891 a 12-1-1892.

(5) AMAE, doc. núm. Sub-A-ll, leg. 2635 de Pol. de Port., con fecha de 7 de agosto de 1891.

(6) AMAE, doc. núm. Sub-A-1ll, leg. 2635 de Pol. de Port., con fecha de 10 de agosto de 1891.

(7) AMAE, doc. núm. Sub-A-IV, leg. 2635 de Pol. de Port., con fecha de 11 de agosto de 1891. 
(8) AMAE, doc. núm. Sub-A-V, leg. 2635 de Pol. de Port., con fecha de 2 de agosto de 1891.

(9) AMAE, doc. núm. Sub-A-VI, leg. 2635 de Pol. de Port., con fecha de 12 de agosto de 1891.

(10) AMAE, doc. núm. Sub-A-VII, leg. 2635 de Pol. de Port., con fecha 12 de agosto de 1891.

(11) AMAE, doc. núm. Sub-A-VIII, leg. 2635 de Pol. de Port., con fecha de 22 de agosto de 1891.

(12) AMAE, doc. núm. Sub-A-XII, leg. 2635 de Pol. de Port., con fecha de 18 de agosto de 1891.

(13) AMAE, doc. núm. Sub-A-XIII, leg. 2635 de Pol de Port., con fecha de 22 de agosto de 1891.

(14) AMAE, doc. núm. Sub-A-XIV, leg. 2635 de Pol. de Port., con techa de $7 / 19$ de octubre de 1891.

(15) AMAE, doc. núm. Sub-A-XV, leg. 2635 de Pol de Port., con fecha de noviembre de 1891.

(16) AMAE, doc. núm. Sub-A-XVI, leg. de Pol. de Port., con fecha de $6 / 18$ de diciembre de 1891.

(17) AMAE, doc. núm. Sub-A-XVII, leg. 2635 de Pol de Port., fechado en agosto de 1891.

(18) AMAE, doc. núm. Sub-A-XVIII, leg. 2635 de Pol. de Port., fechado en enero de 1892.

(19) AMAE, doc. núm. Sub-A-XXV, leg. 2635 de Pol. de Port., fechado en septiembre de 1891.

(20) AMAE, doc. núm. Sub-A-XXVI, leg. 2635 de Pol. de Port., fechado en septiembre y octubre de 1891.

(21) AMAE, doc. núm. Sub-A-XXXVIII, leg. 2635 de Pol. de Port., fechado en abril de 1893.

(22) AMAE, doc. núm. Sub-A-XXXIX, leg. 2635 de Pol. de Port., fechado de abril a julio de 1891. 